\title{
Analysis of the Relationship between the Molecular Weight and Transfection Efficiency/Cytotoxicity of Poly-L-arginine on a Mammalian Cell Line
}

\author{
Heebeom Koo, Hyunseo Kang, and Yan Lee \\ School of Chemistry \& Molecular Engineering, Seoul National University. Seoul 151-742, Korea \\ "Division of Clinical Biotechnology, Center for Disease Biology and Integrative Medicine. Graduate School of Medicine.

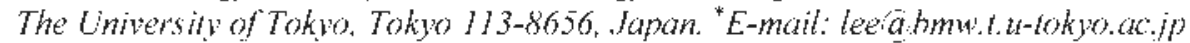 \\ Received December 24, 2008. Accepted February 7, 2009
}

Key Words: Cytotoxicity, Gene delivery, Polyarginine, Polylysine, Transfection

The importance of the intracellular delivery of DNA and RNA has been highlighted for the therapeutic application as well as the fundamental research about the cell mechanism. After the introduction of the concept of gene therapy, ' which involves the production of the therapeutic proteins by the delivery of [DNA into cells and the discovery of siRNA. ${ }^{2}$ which can control the translation of a specific protein, the development of the method for efficient and safe delivery of DNA and RNA has been one of the main objectives in the biological and medical science. Therefore, many chemists has been concentrated their efforts to synthesize the non-viral gene delivery carriers such as cationic lipids, "polymers, and dendrimers ${ }^{5}$ because they have various advantages over biological viral carriers such as easy large-scale production. low immune response, and high safety in the body.

Recently, the TAT sequence," a nucleus localization signal (NI.S) peptide sequence of the human immunodeficiency virus (HIV), has been applied to the improvement of efficiency of gene delivery carriers. With a help of the arginine-rich TAT sequence, various biopharmaceuticals including DNA could be delivered to cell nucleus, where the transcription of RNA from the DNA template occurs. Other similar arginine-rich peptide sequences were also reported to show significant nucleus localization of internal cargos in various non-viral gene carriers. ${ }^{7}$ Moreover, the polymer or dendrimer modified with $\operatorname{arginine}^{8}$ or guanidine ${ }^{9}$ showed highly improved gene delivery efficiency.

Poly-L-arginine (PArg) (Figure 1A) was also applied as the gene delivery carriers based on the reports above. ${ }^{(1)}$ However. although the characteristics of its lysine derivative, poly-L,- lysine (PL.L) (Figure 1A), was examined profoundly in terms of the molecular weight, transfection efficiency, and cytotoxicity, "the comprehensive research about the relationship between the molecular weight of PArg and its biological activity has not been performed yet. Here, we wish to show the advantages of PArg over PI I . through the examination of the physicochemical characteristics and the biological activity.

PArg polymers with three different molecular weights were purchased from Sigma (St. Louis, MO). Although the molecular weights are informed from the distributor, the accuracy is not adequate for the systematic research. Therefore, we re-confirmed the molecular weights by multi angle laser light scattering (MAl_ls) method. As shown in Table 1 , the $M_{w}$ (weight-averaged molecular weight) values of $10 \mathrm{kDa}, 4]$ $\mathrm{kDa}$, and $83 \mathrm{k}$ )a were measured by MAl.l.S, of which accuracy and precision are quite different from the values of the distributor. The molecular weights of PArg polyners are between $10 \mathrm{kDa}$ and $100 \mathrm{kDa}$, the range of the nolecular weights of most of polymers for gene delivery. The $\operatorname{PD}\left(M_{43} / M_{n 1}\right)$ of the $10 \mathrm{kDa}$ PArg was 1.838 , which showed moderately narrow distribution, and the PDs of $4 \mathrm{l} \mathrm{kDa}$ and $83 \mathrm{kDa}$ PArgs were 1.140 and 1.042 , respectively, which showed narrow distribution.

The transfection efficiencies on human embryonic kidney (HГK) 293 cells of PArg polymers were compared according to the variation of their molecular weights by using luciferase plsamid. The high-molecular-weight PAres polymers ( $41 \mathrm{kDa}$ and $83 \mathrm{kDa}$ ) showed about 100 times higher transfection efficiency than the low-molecular-weight PArg (10 kDa) (Figure 1B). The transfection efficiency was dependent upon
A<smiles>CNC(=O)C(CCCNC(=N)N)C(C)C</smiles>

Poly-L-arginine (PArg)

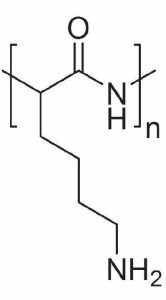

Poly-L-lysine (PLL)
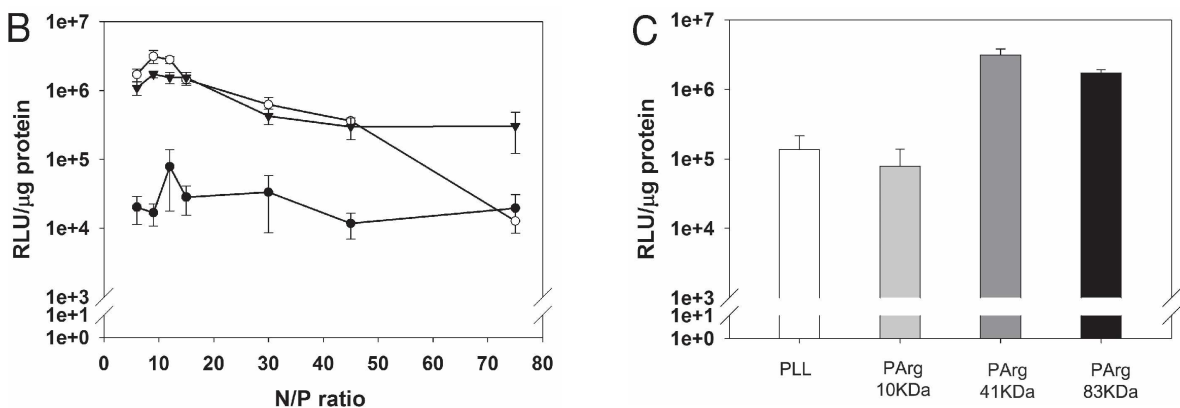

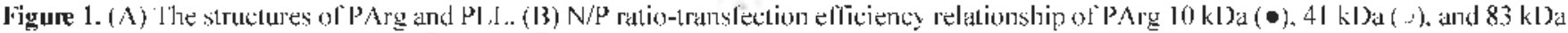
(v). (C) The comparison of the transfeetion efficiency between PLL and PArg polymers at their optimal ratios. Each error bar represents standard deviation ( - S. D.). 
Table 1. The molecular weight measurement of PArg and PLL

\begin{tabular}{|c|c|c|c|c|c|}
\hline & $\mathrm{M}_{11}{ }^{\prime \prime}$ & $\mathrm{M}^{b}{ }^{b}$ & $\mathrm{M}_{5 i}^{b}$ & $\mathrm{PD}\left(\mathrm{M}_{\mathfrak{v}} / \mathrm{M}_{r}\right)^{b}$ & $\mathrm{~d} n / \mathrm{dc}(\mathrm{mL} / \mathrm{g})$ \\
\hline PArg $10 \mathrm{kDa}$ & $5,000-15,000$ & 10,360 & 5,639 & 1.838 & 0.1968 \\
\hline PArg $4 \mathrm{lkDa}$ & $15,000-70,000$ & 41.340 & 36.280 & 1.140 & 0.1422 \\
\hline PArg $83 \mathrm{kDa}$ & $>70.0000$ & 82.840 & 79.520 & 1.042 & 0.1499 \\
\hline PI.I. & $30.000-70.000$ & 46.760 & 24.530 & 1.906 & 0.1769 \\
\hline
\end{tabular}

"referenced from the producer catalogues. "measured by MALLS.
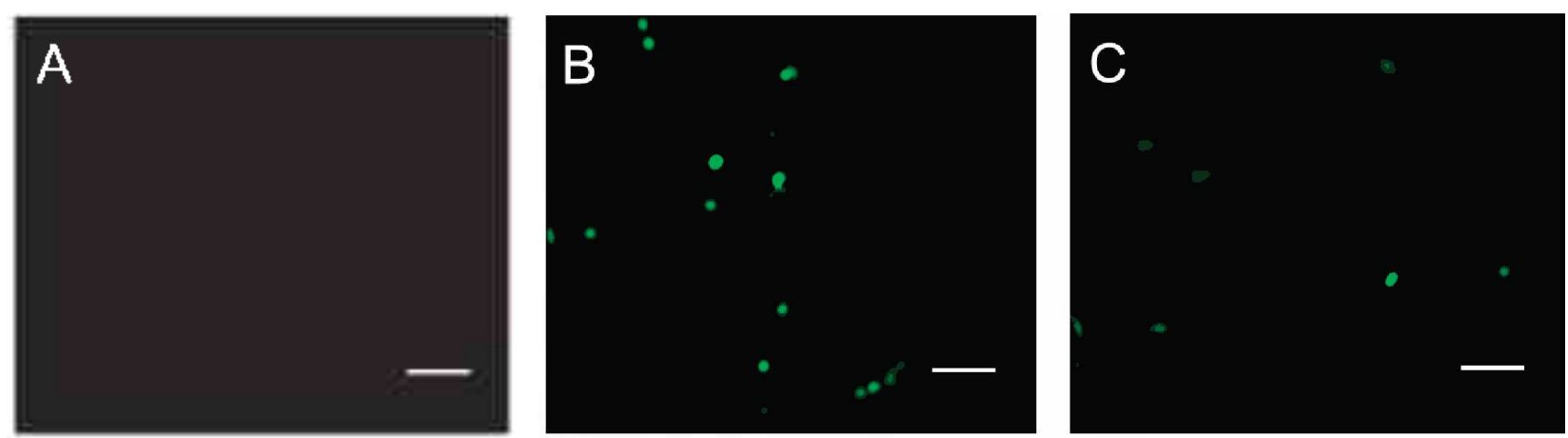

Figure 2. Fluorescence microscopic images of HEK 293 cells transfected with the pols plex between pEGFP and (A) PArg l0 kDa. (B) $41 \mathrm{kDa}$. and (C) $83 \mathrm{kDa}$. Each bar represents $100 \mu \mathrm{m}$.

the guanidine $(\mathrm{N})$ to phosphate $(\mathrm{P})$ ratios. All threc PArg polymers showed their maximum transfection efficiency at the $N / P$ ratio of around 10 . The transtection efficiency of PArg was also compared with that of PLL (Figure l(). Because it was reported that the transfection efficiency of the highmolecular-weight PLL (over $20 \mathrm{kDa}$ ) showed significantly higher transfection efficiency than that of the low-molecularweight PLL, "we chose the $47 \mathrm{kDa}$ PLL with a similar molccular weight with $41 \mathrm{kDa}$ PArg, as a control. At their optimal N/P ratios, the PArg $(41 \mathrm{kDa})$ showed over 10 times higher transfection efficiency than PLL.

The difference of the transfection efficiency depending upon the molecular weight can be also confirmed using the plasmid coding enhanced green fluorescence protein (EGH'P) gene. The 293 celles transfected with PArg $10 \mathrm{kDa}$ showed almost no green fluorescence (Figure 2A), whereas, the cells transfected with PArg 41 kDa showed bright green fluorescence (Figure 2B). The intensity of the green fluorescence in the cells transfected with Arg $83 \mathrm{kDa}$ was slightly weaker (Figure 2C).

Next, we have compared the stability of the polymer-DNA complex (polyplex) of PArg and PLL. The polyplexes at the $\mathrm{N} P$ ratio of 9 , the optimal ratio for the transfection, were trealed with various amounts of heparin, an anionic macromolecule to dissociate DNA from polyplexes by competing with DNA through electrostatic interaction. "' The stability of the polyplex against the addition of heparin was analyzed by agarose gel retardation assay (Figure 3). The PLL polyplex released DNA at the $1.0 \mathrm{mg} / \mathrm{mL}$ of heparin, whereas, the PArg polyplex show almost no release up to $1.5 \mathrm{mg} / \mathrm{mL}$ of heparin. The higher basicity of the guanidine $(\mathrm{pKa}-12.5)$ in $\mathrm{P}^{\mathrm{A}} \mathrm{Ar} \mathrm{g}$ over the amine $(\mathrm{pKa}=10.7)$ in PLL and the additional hydrogen bonds belween the phosphates in DNA and guanidines in PArg are probably the main reasons for the enhanced stability of PArg polyplex. Although the main reason of the higher transfection elficiency of PArg over PLL was the plasma membrane penetrating activity and nucleus localization activity of PArg, ${ }^{13}$ the higher stability of the PArg polyplex against anionic molecules in the extracellular matrix could also support the higher efficiency.

Finally, the cytotoxicities of PArg polymers were compared according to the variation of molecular weight (Figure 4). Similarly to other cationic polymers for the gene delivery, the higher-molecular-weight PArg showed higher cytotoxicity. PArg $10 \mathrm{kDa}$ showed almost no cytotoxicity even at 100 $\mu \mathrm{g} / \mathrm{mL}$. However, the $\left[\mathrm{C}_{51)}\right.$ value of PArg $41 \mathrm{kDa}$ is around $100 \mu \mathrm{g} / \mathrm{mL}$, and that of PArg $83 \mathrm{kDa}$ is around $70 \mu \mathrm{g} / \mathrm{mL}$. Considering that the $\mathrm{IC}_{50}$ value of PLL was reported as below $20 \mu \mathrm{g} / \mathrm{mL}^{\text {l1 }}$ the PArg can be promising as a nontoxic and efficient gene delivery carrier. Selection of the optimal molecular weight among P'Arg polymers for both high 1ransfection efficiency and low cytotoxicity should be essential for the successful gene delivery.
A

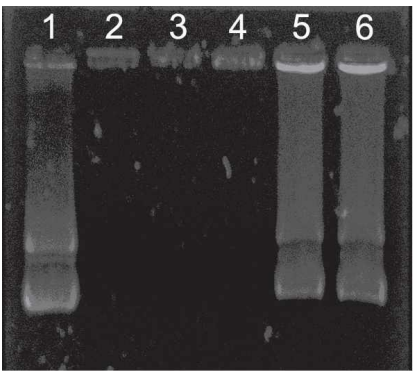

$\mathrm{B}$

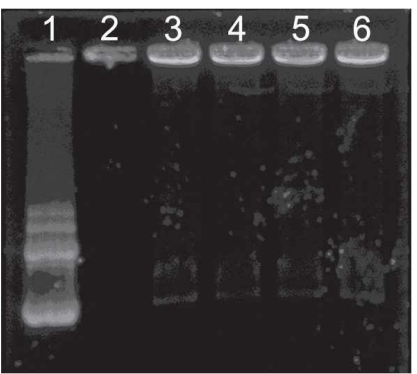

Figure 3. The stabilits of the PLL (A) and PArg (B) polvplexes agsainst the addition of heparin. The lane $1,2,3.4$. 5. and 6 represent DNA only. polyplex only. polyplex added by $0.3 \mathrm{mg} / \mathrm{ml}$. heparin. pols plex added by $0.7 \mathrm{mg} / \mathrm{mL}$ licparim. polsplex added by $1.0 \mathrm{mg} / \mathrm{mL}$ heparin, and pol plex added by $1.5 \mathrm{mg} / \mathrm{mL}$ heparin, respectively 


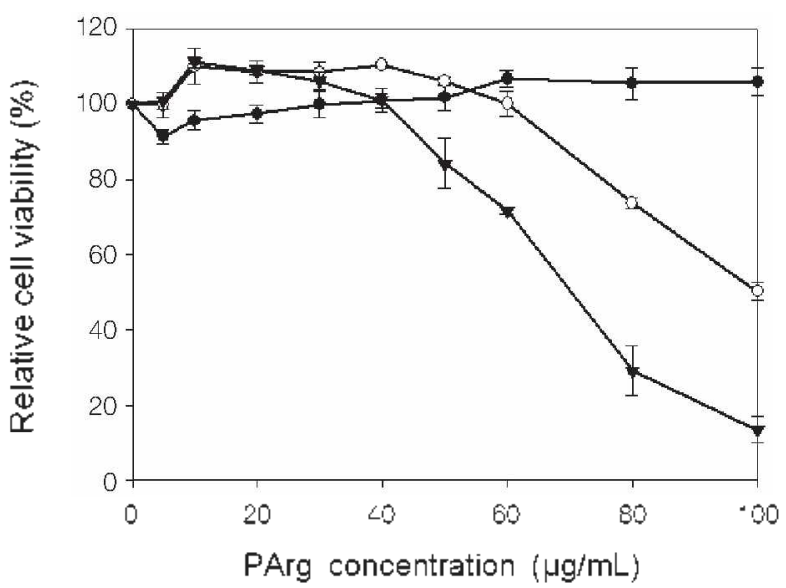

Figure 4 . The cy totoxicity on 293 cells of PArg $10 \mathrm{kDa}(\bullet), 41 \mathrm{kDa}$ $(0)$, and $83 \mathrm{kDa}(\nabla)$. Each error bar represents standard deviation (土S. D.)

In summary. we examined the transfection efficiency and cytotoxicity of PArg polymers and confirmed the relationship between the molecular weight and the potential for the DNA delivery. PArg has also been applied for the specific repression of the protein production by siRNA delivery ${ }^{1+4} \mathrm{By}$ controlling and selection of the optimal molecular weight for biological use as reported here. PArg would have great potential as a biocompatible and functional polymers for DNA and siRNA delivery in the medical field as well as the biological field

\section{Experimental Section}

Molecular weight measurement of PArg by MALLS. Each molecular weight was determined by MALLS in combination with size-exclusion chromatography (SEC). ${ }^{15}$ The SEC system included a P680 HPLC pump from Dionex Corporation (USA). Polymer samples were detected by a three-angle laser-light-scattering detector (miniDAWN Tristar. $30 \mathrm{~mW}$ GaAs laser. $690 \mathrm{~nm} . \mathrm{K} 5$ cell) and an interferometric refractometer (Optilab DSP. PI0 cell) from Wyatt Technologies (USA). A $1 \%$ formic acid aqueous solution was used as an eluent after filtration through a 22-nm filter and degassing. The $\mathrm{d} n / \mathrm{d} c$ value for each poly mer was also measured by the same interferometric refractometer.

Transfection assay in the HEK 293 cell line. The HEK 293 cells were seeded at a density of $3 \times 10^{+}$cells/well in 24 -well plates with $600 \mu \mathrm{L}$ of Dulbecco's modified Eagle's medium (DMEM) (Cambrex Bio Science. USA) containing 10\% Fatal Bovine Serum (FBS) (GIBCO. USA) and grown to $70-80 \%$ confluence for one day. The cells in each well was treated with polyplex solution containing $2 \mu \mathrm{g}$ of pCN-Luci plasmid DNA at various N/P ratios for $4 \mathrm{~h}$ at $37^{\circ} \mathrm{C} . .^{16}$ Following 4 h-treatment of polyplexes. the medium was replaced by $600 \mu \mathrm{L}$ of fresh medium containing $10 \%$ FBS. After an additional incubation for 2 days. the growth medium was removed. The cells were rinsed with $240 \mu \mathrm{L}$ of phosphate buffered saline (PBS) and lysed for $30 \mathrm{~min}$ at room temperature by using $120 \mu \mathrm{L}$ of reporter lysis buffer (Promega. USA). The luciferase activity was measured using a LB 9507 luminometer (Berthold. Germany). and the protein content was measured by using a
Micro BCA assay reagent kit (Pierce. Rockford. IL). The same transfection method was used for the pEGFP-C2 DNA delivery. The fluorescent images were observed and recorded with Axiovert 200M Carl Zeiss microscope

Polyplex stability assay. The polyplex solutions ( $10 \mathrm{mM}$ Hepes. $1 \mathrm{mM} \mathrm{NaCl} . \mathrm{pH} 7.4$ ) containing $1 \mu \mathrm{g}$ DNA were prepared at an N/P ratio of 9 . After 30 min incubation at room temperature for the polyplex formation, various amounts of heparin solution was added to the polyplex solutions. After an additional 30 min-incubation. the samples were electrophoresed on a $0.7 \%(w / v)$ agarose gel and stained with an ethidium bromide solution $(0.5 \mu \mathrm{g} / \mathrm{mL})$. The location of the DNA was analyzed on a UV illuninator.

Cytotoxicity assay. 3-[4.5-Dimethylthiazol-2-yl]-2.5-diphenyl tetrazolium bromide (MTT) assay was used to measure cytotoxicity. HEK 293 cells were seeded in 96-well tissue culture plates at a density of $8 \times 10^{3}$ cells/well in $90 \mu \mathrm{L}$ DMEM medium containing $10 \%$ FBS. The cells achieving $70-80 \%$ confluence after $24 \mathrm{~h}$ were exposed to $10 \mu \mathrm{L}$ of various concentrations of the poly mer solutions for 4 h. $26 \mu \mathrm{L}$ of the solution of MTT (Sigma. USA) ( $2 \mathrm{mg} / \mathrm{mL}$ in PBS) was added to each well. After an additional $2 \mathrm{~h}$-incubation at 37 ${ }^{\circ} \mathrm{C}$, the media was removed, and the resulting formazan was dissolved with $150 \mu \mathrm{L}$ of dimethylsulfoxide (DMSO). The absorbance was measured at $570 \mathrm{~nm}$ by using a microplate reader (Molecular Devices Company. USA). The relative cell viability was calculated as a percent absorbance to untreated control cells.

Aclnowledgments. We thank So Youn Shim. Won-kyu Lhim and Young Kwang Lee (School of Chemistry \& Molecular Engineering. Seoul National University) for their help for the fluorescence nucroscopy. This work was supported by the Gene Therapy Project of the Ministry of Science and Technology (M10534030004-08N3403-00410).

\section{References}

1. Morgan, R. A.; Anderson, W. F. Anm Rev. Biochem. 1993, 62, 191.

2. Fire, A.; Xu, S.: Montgomery, M. K.: Kostals, S. A.: Driver, S E.; Mello, C. C. Nattire 1998, 391, 806.

3. (a) Felgner, P. L.; Ringold, G. M. Nature 1989, 337, 387, (b) Lee, Y.: Koo, H.: Lim, Y.: Lee, Y.: Mo, H.: Park, T. Bioorg. Med. Chem. Lett. 2004, 14, 2637.

4. (a) Boussif, O.: Lezonalc'h, F.: Zanta, M. A.: Mergny, M. D.; Scheman, D.; Demeneix; B.; Behr, T. P. Proc. Katl. Acad Sci. 1995, 92, 7297. (b) Lim, Y.; Kim, S.-M.; Lee, Y.; Lee, W.; Yang, T.: Lee, M.: Suh, H.: Park, I. J. Am. Chem. Soc. 2001, 123, 2460. (c) Lee, Y.: Mo, H.: Koo, H.; Park, I.-Y.: Cho, M. Y.: Jin, G.; Park, J.-S. Bioconjugate Chen. 2007,18,13.

5. (a) Hudde, T:; Ravner, S. A.; Comer, R. M: Weber, M:; Isaacs, J. D.: Waldmann, H.: Larkin, D. F. P. Gene Ther 1999, 6, 939. (b) Lee, J. H.; Lim, Y.: Choi, J. S.; Lee, Y.: Kim, T.; Kim, H. I.; Yoon, T. K; Kim, K.; Park, J. Bioconjugate Chem, 2003 , 14, 1214. 6. Green, M: Lowenstein, P. M. Cell 1988, 55, 1179.

7. Wender, P. A.; Mitchell, D. J.; Pattabiraman, K.; Pelkey, E. T.; Steinman, L.: Rothbard, I. B. Proc. Natl Acad. Sci. 2000, 97. 13003 .

8. (a) Choi, J. S.; Nam, K.; Park, J.-Y; Kim, J.-B.; Lee, J.-K. Park, J.-S. J. Controlled Rel 2004, 99, 445. (b) Nam, H. Y, Hahn. H. 
J.: Nam, K.; Choi, W.-H.; Teong, Y,; Kinn, D.-E.; Park, T-S. Int. J. Pham 2008, 363, 199.

9. (a) Fundhoff, A. M.: Nostrum, C. F.; Lok, M. C.; Fretz, M. M.: Crommelin, D. I. A.: Hennink, W. E. Bioconjugate Chent. 2004, I5, 1212. (b) Lee, Y.; Cho, M. Y: Mo, H.: Nam, K.: Koo, H.; Jin, G.: Park, T. S. Bull Kor. Chem. Soc. 2008, 29,666.

10. (a) Pouton, C. W.: Lucas, P.; Thomas, B. J.: Uduehi, A. N.: Milroy, D. A.; Moss, S. H. J. Controlled. Rel. 1998, 53, 289. (b) Hess, G. T: Humphries, W. H.; Fay, N. C.; Payne, C. K. Biochim. Biophss. Acta-ihol Cell Res. 2007, 1773, 1583.

11. (a) Lee, M.; Nah, J.-W.: Kwon, Y.; Koh, J. J.: Ko, K. S.; Kim, S. W. Pham Res. 2001, 19, 427. (b) Mannisto, M: Vanderkerken, S.; Toncheva, V.: Elomaa, M.; Ruponen, M.; Schacht, E.; Urtti,
A. J. Controlled Rel. 2002, 83, 169.

12. Moret, I.: Peris, I. E.: Guillem, V. M.; Benet, M.; Revert, F.; Dsai, F.; Crespo, A.; Alino, S. F. J. Controlled Rel. 2001, 76. 169 .

13. Vives, E.; Brodin, P.; Lebleu, B. J. Biol. Chent 1997, 272, 16010 .

14. Zhang, C.; Tang, N.; Liu, X; Liang, W.; Xu, W.; Torchilin, V.P. J. Controlled Rel. 2006, 112, 229.

15. Kim, H. J.: Kwon, M. S.: Choi, J. S.: Kim, B. H.; Yoon, J. K.; Kim, K.: Park, I. Bull Kor: Chem. Soc. 2007, 28,63.

16. Kim, H. J.: Kwon, M. S.: Choi, J. S.: Yang, S. M.; Yoon, I. K.; Kim, K.; Park, J. Biomatentals 2006, 27, 2292. 